\title{
Approaches to drug therapy for COPD in Russia: a proposed therapeutic algorithm
}

\author{
This article was published in the following Dove Press journal: \\ International Journal of COPD \\ II April 2017 \\ Number of times this article has been viewed
}

\author{
Kirill A Zykov' \\ Svetlana I Ovcharenko² \\ 'Laboratory of Pulmonology, Moscow \\ State University of Medicine and \\ Dentistry named after A.I. Evdokimov, \\ ${ }^{2}$ I.M. Sechenov First Moscow State \\ Medical University, Moscow, Russia
}

\begin{abstract}
Until recently, there have been few clinical algorithms for the management of patients with COPD. Current evidence-based clinical management guidelines can appear to be complex, and they lack clear step-by-step instructions. For these reasons, we chose to create a simple and practical clinical algorithm for the management of patients with COPD, which would be applicable to real-world clinical practice, and which was based on clinical symptoms and spirometric parameters that would take into account the pathophysiological heterogeneity of COPD. This optimized algorithm has two main fields, one for nonspecialist treatment by primary care and general physicians and the other for treatment by specialized pulmonologists. Patients with COPD are treated with long-acting bronchodilators and short-acting drugs on a demand basis. If the forced expiratory volume in one second $\left(\mathrm{FEV}_{1}\right)$ is $\geq 50 \%$ of predicted and symptoms are mild, treatment with a single long-acting muscarinic antagonist or long-acting beta-agonist is proposed. When $\mathrm{FEV}_{1}$ is $<50 \%$ of predicted and/or the COPD assessment test score is $\geq 10$, the use of combined bronchodilators is advised. If there is no response to treatment after three months, referral to a pulmonary specialist is recommended for pathophysiological endotyping: 1) eosinophilic endotype with peripheral blood or sputum eosinophilia $>3 \%$; 2) neutrophilic endotype with peripheral blood neutrophilia $>60 \%$ or green sputum; or 3) pauci-granulocytic endotype. It is hoped that this simple, optimized, step-by-step algorithm will help to individualize the treatment of COPD in real-world clinical practice. This algorithm has yet to be evaluated prospectively or by comparison with other COPD management algorithms, including its effects on patient treatment outcomes. However, it is hoped that this algorithm may be useful in daily clinical practice for physicians treating patients with COPD in Russia.
\end{abstract}

Keywords: bronchodilators, COPD, treatment algorithm, spirometry, symptoms, treatment

\section{Introduction}

COPD is a major cause of morbidity and mortality, which in 2010 was reported to be the third leading cause of mortality worldwide. ${ }^{1}$ However, published and official statistics data do not reflect the real situation of COPD in Russia, because only the severe forms of the disease are diagnosed, and patients with mild symptoms are often not correctly diagnosed or included in health data. ${ }^{2}$ Recently published data on COPD in Russia between 2012 and 2013 have reported an overall prevalence of $9 \% .^{3}$ In 2014, a clinical study showed that in 12 regions in Russia, the prevalence of COPD diagnosed by spirometry in patients with respiratory symptoms was $21.8 \%{ }^{4}$ Furthermore, in Russia, only $19.8 \%$ of women and $35.6 \%$ of men with clinically proven COPD have had a medical diagnosis of COPD. ${ }^{5}$ More than $90 \%$ of patients in Russia who are diagnosed with COPD are not treated in accordance with current clinical guidelines., ${ }^{4,6}$
Correspondence: Kirill A Zykov Laboratory of Pulmonology, Moscow State University of Medicine and Dentistry named after A.I. Evdokimov, Delegatskaya Street 20/I, Moscow 127473, Russia

Tel +79257729462

Fax+74954I46I35

Email kirillaz@inbox.ru 
One of the most important tasks to be accomplished to improve the quality of management for patients with COPD is the development of effective treatment algorithms, which are simple to use, not only for pulmonary specialists but also for general practitioners, in real-world clinical practice. In Russia, COPD cannot be treated exclusively by pulmonologists, as there are only 2,500 pulmonary specialists for a population of $>145$ million. Therefore, it is important that primary care and general physicians should be able to diagnose COPD, prescribe initial therapy, and correct the existing treatment, if required. For all these reasons, developing effective diagnostic and therapeutic algorithms for COPD and implementing their use in clinical practice is important in Russia. The main requirement of such clinical management algorithms is that they should comply with current evidence-based COPD therapy; in addition, they should be simple to use in clinical practice, not only by respiratory specialists but also by primary care and general physicians. This article discusses the main issues in the diagnosis and management of COPD as they relate to the development of a clinical management algorithm that can be used in real-world clinical practice to improve the health of patients with COPD in Russia.

\section{Current international and Russian COPD management guidelines: principles of disease assessment}

For developing a clinical management algorithm for COPD, it is important to know which clinical algorithms or guidelines are used by physicians when choosing the most appropriate drug therapy for the management of stable COPD. Before 2011, physicians would choose drug treatment for patients with COPD based on the findings from forced expiratory volume in one second $\left(\mathrm{FEV}_{1}\right)$; the severity of COPD was evaluated according to the simple spirometric grading system. ${ }^{7}$ In fact, the algorithmic approach to administration of COPD drug therapy in compliance with this regimen was unequivocal, with a straightforward sequential step-up therapy, which increased if spirometric values worsened. The steady decline in $\mathrm{FEV}_{1}$ in patients with COPD has long been perceived as dogma. However, this belief was challenged by evidence from controlled clinical studies. ${ }^{8}$ It has been shown that $\mathrm{FEV}_{1}$ is an unreliable marker of the severity of breathlessness, exercise limitation, and impaired health status. ${ }^{9}$ Despite the simplicity of the use of $\mathrm{FEV}_{1}$ alone in guiding patient management, airflow obstruction alone is not an indicator of the severity of COPD. In 2011, the Global Initiative for Chronic Obstructive Lung Disease (GOLD) proposed a combined assessment of COPD. ${ }^{10}$ In this new classification, three main components were taken into account: spirometric parameters, the severity of clinical symptoms, and the frequency of exacerbations. ${ }^{10}$

Patient management based on phenotypic classification of COPD has previously been proposed in several countries. ${ }^{11}$ In 2014, the Russian Respiratory Society clinical recommendations for the diagnosis and treatment of COPD included the use of a classification system to direct patient management, which included the four COPD phenotypes, namely, bronchitic, emphysematous, frequent exacerbations, and asthma-COPD overlap syndrome. The severity of clinical symptoms of COPD may be evaluated using one of the standard clinical patient questionnaires, including the modified Medical Research Council (mMRC) dyspnea scale, the COPD assessment test (CAT), or the clinical COPD questionnaire (CCQ). ${ }^{12}$ This proposed evaluation approach appears to be a thorough approach in academic terms, providing as much data as possible, but it may not be applicable or practical in real-world clinical practice. Most physician-patient interactions are limited not only by time but also by health care costs.

Table 1 demonstrates that current guidelines recommend a variety of drug treatments for COPD that require appropriate patient selection. In all parts of the world, including Russia, the choice of drug may not be clear, because the patient group may not be obvious. This factor may cast doubt on the ability of nonspecialists to prescribe appropriate drug treatment for COPD.

The question remains as to whether it may be possible to optimize the approach to COPD therapy. A possible solution is to compromise between the complexity and heterogeneity of the pathophysiology of COPD and the time-limited and resource-limited requirements of realworld clinical practice. An example of such a practical approach is the clinical algorithm used in Japan. ${ }^{13}$ According to this algorithm, the therapy should be based on the complex analysis of COPD, taking into account symptoms and spirometry data. ${ }^{13}$ In cases of repeated exacerbations of COPD, inhaled corticosteroids (ICSs) may be added to the bronchodilators. ${ }^{13}$ This algorithm is presented in the form of the simple decision-making pattern, and the key element for prescribing therapy is symptom severity, as exacerbation rate and the presence of asthma are crucial for ICSs prescribing in COPD. ${ }^{14}$

In 2015, Cooper and Barjaktarevic developed and published one of the most cited clinical algorithms for COPD for use by the US physicians. ${ }^{15}$ This algorithm uses the following clinical phenotypic categories: allergic, bronchitic, infective, bronchiectatic, exacerbated, symptomatic, emphysematous, debilitated, congestive, and vasculopathic. ${ }^{15}$ 
Table I Drug combinations used for the treatment of patients with COPD

\begin{tabular}{lll}
\hline Patient characteristics & First choice & Alternative choice \\
\hline Low risk, less symptoms & SAMA as needed or SABA as needed & LAMA or LABA or SABA and SAMA \\
Low risk, more symptoms & LAMA or LABA & LAMA and LABA \\
High risk, less symptoms & ICSs + LABA or LAMA & LAMA and LABA or LAMA and PDE4 \\
& & inhibitor or LABA and PDE4 inhibitor \\
High risk, more symptoms & ICSs + LABA and/or LAMA & ICSs + LABA and LAMA or ICSs + LABA and \\
& & PDE4 inhibitor or LAMA and LABA or LAMA \\
& & and PDE4 inhibitor
\end{tabular}

Note: Data from Federal clinical recommendations for diagnostics and treatment of chronic obstructive pulmonary disease. Russian Respiratory Society; 20 I4. ${ }^{2}$

Abbreviations: ICS, inhaled corticosteroid; LABA, long-acting beta-agonist; LAMA, long-acting muscarinic antagonist; PDE4, phosphodiesterase-4; SABA, short-acting beta-agonist; SAMA, short-acting muscarinic antagonist.

The key approach used in this algorithm is to determine the clinical stage of the disease at the outset, as patients with an $\mathrm{FEV}_{1}>80 \%$ of that predicted, and those who have intermittent symptoms, are offered short-acting bronchodilators, as single agents or in combination. ${ }^{15}$ If airflow obstruction and symptoms worsen, the algorithm recommends initial treatment with long-acting bronchodilators combined with short-acting drugs, and then the combination of a longacting muscarinic antagonist (LAMA) and a long-acting beta-agonist (LABA). ${ }^{15}$ If the efficacy is insufficient and the patient has frequent exacerbations and no improvement in airflow obstruction, then the possibility of phenotyping with a more "personalized" treatment approach is considered. ${ }^{15}$ It is important to note that ICSs are not included in this algorithm unless phenotyping indicates a treatment requirement. ${ }^{15}$ This algorithmic approach is of interest and has been developed for use in the USA, but the use of a large and complicated phenotyping component would make this difficult to implement in real-world practice in Russia.

Taking into account the differences in these approaches for the selection of COPD therapy that currently exist in various countries, it is clear that there is no clinical consensus and the issue is far from being resolved. Each of the algorithms has its strengths and weaknesses. When establishing our own suggestions, we tried to take these factors into account and to combine the strengths of the existing approaches, while developing a more practical form of clinical algorithm.

\section{Points to consider for proposing an algorithm for COPD treatment in real-world clinical practice}

Our goal of creating an algorithm for the management of patients with COPD, including drug therapy, that can be easily used by practicing physicians is to facilitate both the initial selection of medications to be prescribed and the change of therapy at the further stages of the disease. The algorithm should be simple to use in real-world clinical practice, not only by respiratory specialists but also by general practitioners. The proposed algorithm is presented in Figure 1, and is based on three main components: 1) parameters that define the selection of therapy; 2) proposed therapeutic solutions; and 3) the level of the therapeutic decision making (either pulmonologists or general physicians not specialized in respiratory medicine).

When determining the therapeutic approach for the patient with an established diagnosis of COPD, the physician may follow the algorithm, as shown in Figure 1. It is necessary to evaluate the parameters that determine the selection of the therapy: post-bronchodilator $\mathrm{FEV}_{1}$ and the magnitude of the patient's symptoms using the CAT questionnaire. The importance of the spirometry diagnostic evaluation is assumed, since the evaluation of spirometric values is necessary to confirm the diagnosis of COPD. ${ }^{10}$ The post-bronchodilator $\mathrm{FEV}_{1}<50 \%$ of the normal value is associated with elevated risk of the COPD exacerbations. ${ }^{10,16-18}$

Evaluation of patient symptoms is a key component of patient management included in this algorithm. Current clinical guidelines support the use of several questionnaires for evaluating symptoms, including the mMRC, CAT, and CCQ. ${ }^{7,10}$ In practice, the mMRC and CAT are used most often. However, in the development of this algorithm, it is important to question the use of the patient questionnaires. Some studies have shown that if the same patient cohort is evaluated by both mMRC and CAT, the results of symptom categories and grades differ significantly between the two forms of assessment. ${ }^{19}$ Therefore, these questionnaires are not interchangeable, and it was necessary to identify which one to incorporate into the algorithm. The mMRC questionnaire is the lesser time-consuming of the two, but there are doubts about its clinical diagnostic use as it defines only symptoms such as breathlessness, using a 5-point scale. If the patient has dyspnea caused not by COPD, for example, heart failure as comorbidity, the use of mMRC may lead to the overestimation of the symptoms that may lead to incorrect drug treatment or drug dosing. A further disadvantage of 


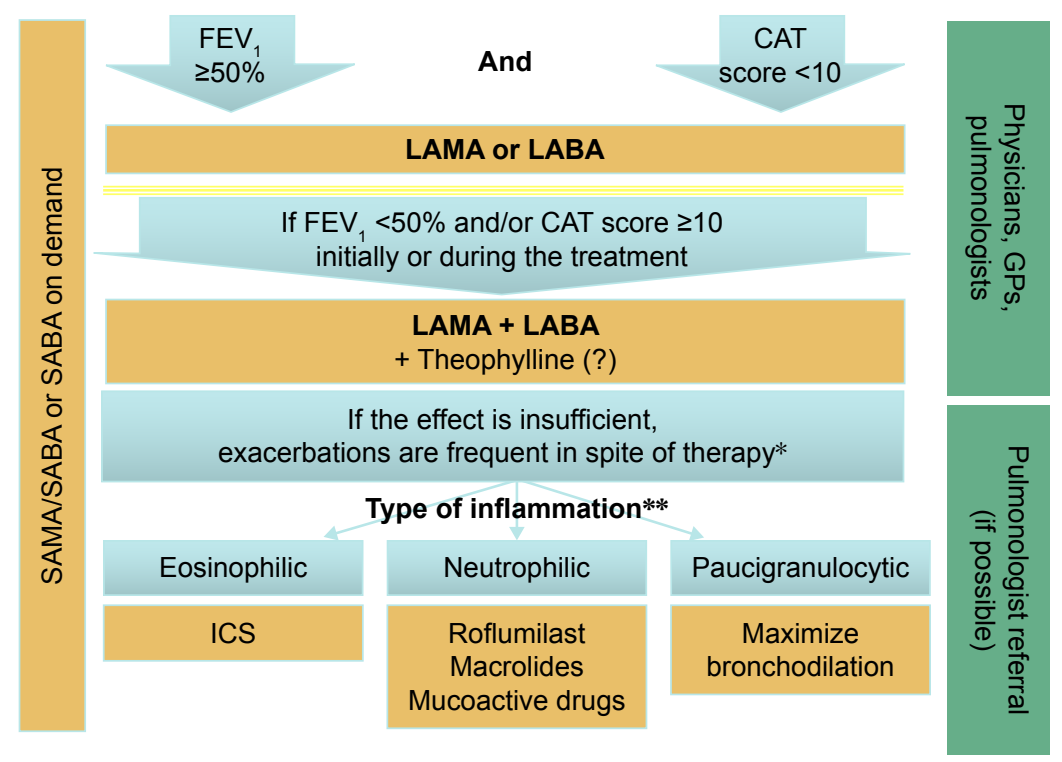

Figure I The proposed algorithm for the management of patients with stable COPD.

Notes: *Evaluation of symptoms is based on the CAT questionnaire, if there was more than one clinical exacerbation or one clinical event leading to hospitalization during one year of follow-up. **Pathophysiological endotyping: I) eosinophilic endotype with peripheral blood eosinophilia or sputum eosinophilia $>3 \%$; 2 ) neutrophilic endotype with peripheral blood neutrophilia of $>60 \%$ or with green sputum; or 3) pauci-granulocytic endotype.

Abbreviations: CAT, COPD assessment test; $\mathrm{FEV}_{1}$, forced expiratory volume in one second; GPs, general physicians; ICS, inhaled corticosteroid; LABA, long-acting betaagonist; LAMA, long-acting muscarinic antagonist; SABA, short-acting beta-agonist; SAMA, short-acting muscarinic antagonist.

mMRC is the absence of assessment of important respiratory symptoms, including cough and amount and purulence of sputum; for evaluation of COPD, the physician is required to ask the patient additional questions to get the complete clinical picture of the disease..$^{20,21}$ The CAT questionnaire is comprehensive, as the patient answers eight questions using a 6-point scale, and these questions deal with the intensity of cough, breathlessness, sputum discharge, quality of sleep, and general state of the patient. When first using this questionnaire, the physician will spend more in explaining how to fill it when compared to mMRC, but afterward no extra time will be needed, since the patient can complete the questionnaire independently, without the physician. Therefore, the CAT questionnaire is recommended for use with this algorithm, because it provides a holistic assessment of the symptoms of the patient with COPD. ${ }^{22}$ When evaluating the patient symptom dynamics, the minimal clinically important change by CAT evaluation is 2 points. ${ }^{23}$

An important clinical treatment goal in the management of patients with COPD is in clinical symptom and comorbidity risk reduction and in the reduction of exacerbations. The number of exacerbations of COPD is an important parameter in the comprehensive evaluation of the condition of the patient. Several studies have demonstrated a link between the number of COPD exacerbations and the acceleration in the decline of the $\mathrm{FEV}_{1}$, reduction in patient quality of life, increase in mortality, and the significant increase in the costs of therapy. ${ }^{24-27}$ Therefore, it is important to understand exactly what an exacerbation of COPD means and how it is diagnosed. GOLD-2016 defines a COPD exacerbation as an acute clinical event that is characterized by the worsening of respiratory symptoms, which is different from normal variations in symptoms; a COPD exacerbation will require a change in drug treatment. ${ }^{10}$ However, there is no typical clinical profile of a COPD exacerbation, and patients may have varying appreciation of what a change in symptoms may mean or how significant it may be, and may not consult their physician when exacerbations occur. ${ }^{26}$ It is clear that documenting the incidence and frequency of COPD exacerbations can be difficult for both patients and physicians. ${ }^{28}$ Although the accepted symptoms of a COPD exacerbation may include dyspnea, cough, and sputum production, the severity of these symptoms may depend on the phenotypical characteristics of the disease. For example, the patients with the emphysematous COPD phenotype may not complain that their cough becomes significantly worse during an exacerbation or that sputum production has increased or become purulent, but increased breathlessness would be noted. The patients with a predominantly bronchitic phenotype may be more aware of an increase in sputum production. It is clear that it can be difficult to quantify these parameters either for the physician or for the patient. ${ }^{29}$ An additional problem arises when the patient has comorbidities of COPD combined with exacerbations, particularly cardiovascular comorbidities, 
as in some cases the symptoms are difficult to distinguish. ${ }^{30}$ The EXAcerbations of Chronic Pulmonary Disease Tool Patient-Reported Outcome (EXACT-PRO) measure is based on a 14-item questionnaire using a personal digital assistant device and has been developed to assist in the diagnosis of COPD exacerbations, but its value has as yet only been demonstrated in clinical trials of COPD. ${ }^{31}$ However, the EXACT-PRO tool has shown that the majority of the COPD exacerbations experienced by patients are unreported to their physician. ${ }^{31}$

In the use of the clinical algorithm for patients with COPD in Russia, there is an important clinical consideration to be aware of, that of the availability of over-the-counter antibiotic medications purchased from pharmacies without a visit to a doctor. As in Russia, nonprescription sales of antibiotics are a serious problem worldwide. ${ }^{32-34}$ This factor makes it difficult, if not impossible, to calculate the exacerbation rate on the basis of antibiotics treatment courses prescribed.

According to current clinical guidelines, hospitalization due to COPD is considered to be a sign of severe exacerbation, but in practice, patients may be hospitalized due to the local social or organizational factors. ${ }^{35}$ In addition, hospitalization due to exacerbations of respiratory symptoms might not be connected with the COPD exacerbation, but with the exacerbation of comorbid disease, usually cardiovascular disease. $^{36}$

\section{Implementing the new COPD algorithm for COPD treatment in real-world clinical practice}

Following consideration of the above clinical guidelines, practical considerations, and points to consider, the following describes the proposed practical implementation of the new algorithm. Within the framework of the proposed algorithm, the initial patient treatment will depend on the patient's degree of airflow obstruction and the severity of symptoms as determined by the CAT score. The risk of frequent COPD exacerbations will be assessed at this stage by assessment of the $\mathrm{FEV}_{1}$ and $\mathrm{CAT}$ questionnaire results. $\mathrm{An} \mathrm{FEV}_{1}<50 \%$ of normal and/or a CAT score $\geq 10$ points is associated with a reduced time to the first COPD exacerbation, as well as with an increase in the frequency of exacerbations. ${ }^{37}$ This proposed parameter is significantly increased in patients during the progression of an exacerbation, as well as in patients with frequent exacerbations. ${ }^{22,38}$ The CAT scores, even during exacerbation, are increased in patients with a history of frequent exacerbations. ${ }^{39}$ Therefore, if the patient does not have increased symptoms (CAT score $<10$ ) and $\mathrm{FEV}_{1} \geq 50 \%$ of normal, prescription of one of the long-acting bronchodilators (LAMA or LABA) is recommended.

The next important issue was to define the place for the short-acting bronchodilators in the stable COPD therapy. International and national guidelines recommend that patients with the low-intensity and intermittent symptoms and who have preserved spirometric parameters $\left(\mathrm{FEV}_{1} \geq 50 \%\right.$ of normal) and rare exacerbations should be prescribed short-acting muscarinic antagonist (SAMA) or short-acting beta-agonist (SABA) as single treatment or in combination as a first choice of maintenance therapy. However, it is our view that long-acting medications should be used as a basic therapy for all patients with an established diagnosis of COPD because of the greater efficacy of these medications compared with the short-acting ones. ${ }^{10}$ It is important to remember that no drug slows down the rate of annual $\mathrm{FEV}_{1}$ decline seen in patients with COPD. However, it has been shown that the use of the LAMA tiotroprium can reduce the decline in $\mathrm{FEV}_{1}$ in patients with stage II COPD. ${ }^{17}$ This finding supports our view that this drug treatment should commence at the early stages of the disease. Thus, early identification and diagnosis of patients with COPD and commencing drug therapy as early as possible with long-acting bronchodilators may slow the progression of COPD, reduce the development of comorbidities, reduce the mortality, and reduce the health care costs in the management of patients with COPD.

SABA, SAMA, or their combination is recommended for use as needed within the framework of this algorithm, and as maintenance therapy only when it is not possible to use the long-acting medications. The use of an SABA + SAMA combination may be more effective than the use of each of these drugs separately and may help to reduce the diurnal variability in $\mathrm{FEV}_{1} \cdot{ }^{40}$ It is possible to use the short-acting bronchodilators in addition to the long-acting drugs since their effectiveness in this situation has been supported by several studies. ${ }^{41,42}$

There is no conclusive proof that LAMA is more effective than LABA, or that LABA is more effective than LAMA, in the treatment of patients with COPD. In addition, it appears to be more reasonable to prescribe LAMA to patients with COPD and cardiovascular comorbidity, as clinical trial data have demonstrated good safety profiles when large patient samples have been used. ${ }^{43}$ There is evidence that LAMA has a more significant impact on the rate of COPD exacerbation when compared with LABA. ${ }^{44,45}$ Therefore, it may be reasonable to use LAMA as initial therapy. But at present, there is insufficient data to support an evidence-based approach. In 2015, Mahler et al 
published the findings of a post hoc meta-analysis of several clinical trials, which showed that in COPD patients without exacerbations during the previous year and with relatively well-preserved lung function, indacaterol had at least the same effect as tiotroprium on spirometric values, health status, and dyspnea. ${ }^{46}$

When considering the practicalities of the use of inhalation medications, the physician has to show the patient how to use the inhaler properly, to maintain the efficacy of the therapy. ${ }^{47,48}$ If the patient has high symptoms (CAT score $\geq 10$ ) or $\mathrm{FEV}_{1}<50 \%$ of normal, that is, at least one of these parameters, two long-acting bronchodilators are recommended, LAMA and LABA, in the form of free or fixed combinations: aclidinium + formoterol, glycopyrronium + indacaterol, tiotropium + olodaterol, or umeclidinium + vilanterol. The combined medications, LAMA and LABA, when compared with monotherapy, have been shown in several clinical trials to have a significant beneficial impact on the symptoms, spirometric values, or exacerbation frequency in COPD; a good safety profile of the combined bronchodilatory therapy has also been demonstrated. ${ }^{49-51}$

For some patients who have been prescribed combination therapy, it is possible to prescribe theophylline in addition to the long-acting bronchodilators. In terms of efficacy, theophylline is significantly inferior to LAMA and LABA and may be prescribed only for patients with an inadequate response to the combined bronchodilatory therapy; this will be based on the judgment of the physician. Due to the narrow therapeutic range of theophylline, it is necessary to monitor the side effects, primarily those involving the cardiovascular system. ${ }^{52-54}$

Because there are no supporting published data to define the drug treatment time points to assess their therapeutic effect in patients with COPD, within the framework of the proposed algorithm, it is recommended that spirometric values and the CAT questionnaire be assessed again, three months following initial drug prescription or any change in therapy. In the judgment of the treating physician, if the efficacy of drug treatment is insufficient, as shown by no reduction in the CAT score, or if there has been more than one exacerbation of COPD during the follow-up period, or there has been an exacerbation of COPD that led to hospitalization during the one-year period of follow-up, it is recommended that the physician should do the following: 1) check and confirm that the initial diagnosis of COPD is correct; 2) exclude asthma; 3) assess the presence and extent of comorbidities; 4) assess possible side effects of the prescribed medications; 5) check that the prescribed inhalers are used correctly and assess treatment compliance; and 6) if any factors that affect the efficacy of drug treatment are identified, correct the treatment and assess treatment efficacy after three months.

If the diagnosis of COPD is confirmed, all comorbidities are taken into account, and the drug treatment is prescribed correctly and is used appropriately by the patient, it will then be necessary to refer the patient for a consultation with a respiratory specialist for assessment of the endotype of underlying inflammatory process and reevaluation of treatment. This further assessment should be conducted outside the COPD exacerbation period and should include the evaluation of clinical and laboratory tests, which may help to allocate the patient to the neutrophilic, eosinophilic, or pauci-granulocytic inflammatory endotype of COPD. In the development of a simple algorithm for the management of patients with COPD, we propose to use an additional endotypic classification system that is based on the findings from routine laboratory tests that are used in real-world clinical practice.

If the sputum has a neutrophil count $>60 \%$, this is in keeping with a neutrophilic endotype. ${ }^{62-65}$ In this case, in addition to the LAMA and LABA combination therapy, the patient may be prescribed a phosphodiesterase-4 inhibitor, such as roflumilast. ${ }^{57}$ Long-term therapy of eight weeks or more may be undertaken with azithromycin or clarithromycin, both of which also have an anti-inflammatory effect. ${ }^{58,59} \mathrm{~N}$-acetylcysteine or carbocysteine may be prescribed as a mucoactive drug. ${ }^{60,61}$ Currently, there are no treatment algorithms for macrolides or mucoactive drugs, and there are no guidelines for dosage regimens, which may be used off-label and only in compliance with local ethical rules.

If the sputum contains $>3 \%$ of eosinophils or peripheral blood eosinophil count exceeds 300-320 cells per microliter, ICSs are recommended. ${ }^{62-65}$ Significant peripheral blood eosinophilia has been reported to range from 150 to 500 cells per microliter. ${ }^{66,67}$ A peripheral blood eosinophil level of 300 cells per microliter has been included in the algorithm; this cell count has a specificity of $76 \%$ and a sensitivity of $60 \%$, in association with sputum eosinophilia. ${ }^{68}$ Having both sputum and peripheral blood levels of eosinophils in the algorithm reflects the fact that not all laboratories will be equipped to detect sputum eosinophils.

If eosinophils or neutrophils are not present in the sputum (pauci-granulocytic endotype), the algorithm recommends that the dosages of the bronchodilatory therapy be increased 
up to the maximum allowed to achieve a clinical effect, but with cautious monitoring for any drug side effects. Currently, there are no supporting published data regarding the clinical significance of the selection of this subgroup. However, a significant proportion of patients with emphysema with no signs of chronic bronchitis may have this pauci-granulocytic type of sputum, and the COPD endotype without a pronounced local inflammatory reaction in bronchial tree.

\section{Conclusion}

We present a holistic approach to the management of COPD within the framework of the proposed algorithm for primary care and general physicians and respiratory specialists. This algorithm is in development as new data accumulate. Many of the recommendations presented in this algorithm are a compromise between scientific and clinical data in the published literature on COPD therapy, with consideration of subgroup heterogeneity in presentation, treatment, and response to treatment, and the requirements of real-world clinical practice. This clinical algorithm has yet to be evaluated prospectively or compared with other algorithms on COPD management, including its effects on patient outcomes. However, it is hoped that this algorithm may be useful in daily clinical practice for physicians treating patients with COPD in Russia.

\section{Disclosure}

The authors report no conflicts of interest in this work.

\section{References}

1. Lozano R, Naghavi M, Foreman K, et al. Global and regional mortality from 235 causes of death for 20 age groups in 1990 and 2010: a systematic analysis for the Global Burden of Disease Study 2010. Lancet. 2012; 380(9859):2095-2128.

2. Ovcharenko SI. Chronic obstructive pulmonary disease: actual situation in Russia and ways to solve the problem. Pulmonology. 2011;2(6):69-72.

3. Landis SH, Muellerova H, Mannino DM, et al. Continuing to Confront COPD International Patient Survey: methods, COPD prevalence, and disease burden in 2012-2013. Int J Chron Obstruct Pulmon Dis. 2014; 9:597-611.

4. Chuchalin AG, Khaltaev N, Antonov NS, et al. Chronic respiratory diseases and risk factors in 12 regions of the Russian Federation. Int $J$ Chron Obstruct Pulmon Dis. 2014;9:963-974.

5. Artyukhov IP, Arshukova IL, Dobretsova EA, Dugina TA, Shulmin AV, Demko IV. Epidemiology of chronic obstructive pulmonary disease: a population-based study in Krasnoyarsk region, Russia. Int J Chron Obstruct Pulmon Dis. 2015;10:1781-1786.

6. World Health Organization. NMH/MND/CPM/13.1. Global alliance against chronic respiratory diseases (GARD). 7th General Meeting, 9-10 July 2012, St. Petersburg, Russia. Geneva: World Health Organization; 2013. Available from: http://www.who.int/gard/publications/GARDGMReportStPetersburg2012.pdf. Accessed February 9, 2017.

7. Rabe KF, Hurd S, Anzueto A, et al; Global Initiative for Chronic Obstructive Lung Disease. Global strategy for the diagnosis, management, and prevention of chronic obstructive pulmonary disease: GOLD executive summary. Am J Respir Crit Care Med. 2007;176(6):532-555.
8. Vestbo J, Edwards LD, Scanlon PD, et al; ECLIPSE Investigators. Changes in forced expiratory volume in 1 second over time in COPD. N Engl J Med. 2011;365(13):1184-1192.

9. Jones PW. Health status and the spiral of decline. COPD. 2009;6(1): $59-63$.

10. Global Initiative for Chronic Obstructive Lung Disease (GOLD). Global strategy for the diagnosis, management and prevention of COPD. 2016. $\mathrm{http}$ //goldcopd.org/global-strategy-diagnosis-management-preventioncopd-2016/. Accessed February 9, 2017.

11. Han MK, Agusti A, Calverley PM, et al. Chronic obstructive pulmonary disease phenotypes: the future of COPD. Am J Respir Crit Care Med. 2010;182(5):598-604.

12. Federal clinical recommendations for diagnostics and treatment of chronic obstructive pulmonary disease. Russian Respiratory Society; 2014. Available from: http://pulmonology.ru/download/COPD 2014may2.doc. Accessed February 9, 2017. Russian.

13. The Japanese Respiratory Society. Guidelines for the Diagnosis and Treatment of COPD. 4th ed. Tokyo: Japanese Respiratory Society; 2013.

14. Hizawa N. LAMA/LABA vs ICS/LABA in the treatment of COPD in Japan based on the disease phenotypes. Int J Chron Obstruct Pulmon Dis. 2015;10:1093-1102.

15. Cooper CB, Barjaktarevic I. A new algorithm for the management of COPD. Lancet Respir Med. 2015;3(4):266-268.

16. Hurst JR, Vestbo J, Anzueto A, et al. Susceptibility to exacerbation in chronic obstructive pulmonary disease. $N$ Engl J Med. 2010;363(12): $1128-1138$.

17. Decramer M, Celli B, Kesten S, Lystig T, Mehra S, Tashkin DP. Effect of tiotropium on outcomes in patients with moderate chronic obstructive pulmonary disease (UPLIFT): a pre-specified subgroup analysis of a randomised controlled trial. Lancet. 2009;374(9696): $1171-1178$.

18. Jenkins CR, Jones PW, Calverley PM, et al. Efficacy of salmeterol/ fluticasone propionate by GOLD stage of chronic obstructive pulmonary disease: analysis from the randomised, placebo-controlled TORCH study. Respir Res. 2009;10:59.

19. Price DB, Baker CL, Zou KH, Higgins VS, Bailey JT, Pike JS. Realworld characterization and differentiation of the Global Initiative for Chronic Obstructive Lung Disease strategy classification. Int J Chron Obstruct Pulmon Dis. 2014;9:551-561.

20. Jones P, Tabberer M, Chen WH. Creating scenarios of the impact of COPD and their relationship to COPD assessment test (CAT ${ }^{\mathrm{TM}}$ ) scores. BMC Pulm Med. 2011;11:42.

21. Jones PW, Adamek L, Nadeau G, Banik N. Comparisons of health status scores with MRC grades in COPD: implications for the GOLD 2011 classification. Eur Respir J. 2013;42(3):647-654.

22. Chetta A, Olivieri D. The COPD Assessment Test in the evaluation of chronic obstructive pulmonary disease exacerbations. Expert Rev Respir Med. 2012;6(4):373-375.

23. Kon SS, Canavan JL, Jones SE, et al. Minimum clinically important difference for the COPD Assessment Test: a prospective analysis. Lancet Respir Med. 2014;2(3):195-203.

24. Donaldson GC, Seemungal TA, Bhowmik A, Wedzicha JA. Relationship between exacerbation frequency and lung function decline in chronic obstructive pulmonary disease. Thorax. 2002;57(10): $847-852$.

25. Kanner RE, Anthonisen NR, Connett JE; Lung Health Study Research Group. Lower respiratory illnesses promote FEV(1) decline in current smokers but not ex-smokers with mild chronic obstructive pulmonary disease: results from the lung health study. Am J Respir Crit Care Med. 2001;164(3):358-364.

26. Kessler R, Ståhl E, Vogelmeier C, et al. Patient understanding, detection, and experience of COPD exacerbations: an observational, interviewbased study. Chest. 2006;130(1):133-142.

27. Spencer S, Calverley PM, Burge PS, Jones PW. Impact of preventing exacerbations on deterioration of health status in COPD. Eur Respir J. 2004;23(5):698-702. 
28. Zhang R, Tan X, He Q, et al. Comparison of symptom and risk assessment methods among patients with chronic obstructive pulmonary disease. Chin Med J (Engl). 2014;127(14):2594-2598.

29. Vestbo J, Hurd SS, Rodriguez-Roisin R. The 2011 revision of the global strategy for the diagnosis, management and prevention of COPD (GOLD)-why and what? Clin Respir J. 2012;6(4):208-214.

30. Roca M, Verduri A, Corbetta L, Clini E, Fabbri LM, Beghé B. Mechanisms of acute exacerbation of respiratory symptoms in chronic obstructive pulmonary disease. Eur J Clin Invest. 2013;43(5): $510-521$.

31. Leidy NK, Murray LT, Monz BU, et al. Measuring respiratory symptoms of COPD: performance of the EXACT-Respiratory Symptoms Tool (E-RS) in three clinical trials. Respir Res. 2014;15:124.

32. Zoorob R, Grigoryan L, Nash S, Trautner BW. Nonprescription antimicrobial use in a primary care population in the United States. Antimicrob Agents Chemother. 2016;60(9):5527-5532.

33. Llor C, Monnet D, Cots J. Small pharmacies are more likely to dispense antibiotics without a medical prescription than large pharmacies in Catalonia, Spain. Euro Surveill. 2010;15(32).

34. Chang J, Ye D, Lv B, et al. Sale of antibiotics without a prescription at community pharmacies in urban China: a multicentre cross-sectional survey. J Antimicrob Chemother. Epub 2017 Jan 6.

35. Laue J, Melbye H, Halvorsen PA, et al. How do general practitioners implement decision-making regarding COPD patients with exacerbations? An international focus group study. Int J Chron Obstruct Pulmon Dis. 2016;11:3109-3119.

36. Beghé B, Verduri A, Roca M, Fabbri LM. Exacerbation of respiratory symptoms in COPD patients may not be exacerbations of COPD. Eur Respir J. 2013;41(4):993-995.

37. Lee SD, Huang MS, Kang J, et al; Investigators of the Predictive Ability of CAT in Acute Exacerbations of COPD (PACE) Study. The COPD assessment test (CAT) assists prediction of COPD exacerbations in high-risk patients. Respir Med. 2014;108(4):600-608.

38. Mackay AJ, Donaldson GC, Patel AR, Jones PW, Hurst JR, Wedzicha JA. Usefulness of the Chronic Obstructive Pulmonary Disease Assessment Test to evaluate severity of COPD exacerbations. Am J Respir Crit Care Med. 2012;185(11):1218-1224.

39. Tu YH, Zhang Y, Fei GH. Utility of the CAT in the therapy assessment of COPD exacerbations in China. BMC Pulm Med. 2014;14:42.

40. Singh D, Zhu CQ, Sharma S, Church A, Kalberg CJ. Daily variation in lung function in COPD patients with combined albuterol and ipratropium: results from a 4-week, randomized, crossover study. Pulm Pharmacol Ther. 2015;31:85-91.

41. Cazzola M, Santus P, D’Adda A, Pizzolato S, Di Marco F, Centanni S. Acute effects of higher than standard doses of salbutamol and ipratropium on tiotropium-induced bronchodilation in patients with stable COPD. Pulm Pharmacol Ther. 2009;22(3):177-182.

42. Cole JM, Sheehan AH, Jordan JK. Concomitant use of ipratropium and tiotropium in chronic obstructive pulmonary disease. Ann Pharmacother. 2012;46(12):1717-1721.

43. Halpin DM, Dahl R, Hallmann C, Mueller A, Tashkin D. Tiotropium HandiHaler $^{\circledR}$ and Respimat ${ }^{\circledR}$ in COPD: a pooled safety analysis. Int $J$ Chron Obstruct Pulmon Dis. 2015;10:239-259.

44. Vogelmeier C, Hederer B, Glaab T, et al; POET-COPD Investigators. Tiotropium versus salmeterol for the prevention of exacerbations of COPD. N Engl J Med. 2011;364(12):1093-1103.

45. Decramer ML, Chapman KR, Dahl R, et al; INVIGORATE investigators. Once-daily indacaterol versus tiotropium for patients with severe chronic obstructive pulmonary disease (INVIGORATE): a randomised, blinded, parallel-group study. Lancet Respir Med. 2013; 1(7):524-533.

46. Mahler DA, Kerstjens HA, Donohue JF, Buhl R, Lawrence D, Altman P. Indacaterol vs tiotropium in COPD patients classified as GOLD A and B. Respir Med. 2015;109(8):1031-1039.

47. Al-Showair RA, Tarsin WY, Assi KH, Pearson SB, Chrystyn H. Can all patients with COPD use the correct inhalation flow with all inhalers and does training help? Respir Med. 2007;101(11):2395-2401.
48. Sriram KB, Percival M. Suboptimal inhaler medication adherence and incorrect technique are common among chronic obstructive pulmonary disease patients. Chron Respir Dis. 2016;13(1):13-22.

49. Buhl R, Maltais F, Abrahams R, et al. Tiotropium and olodaterol fixeddose combination versus mono-components in COPD (GOLD 2-4). Eur Respir J. 2015;45(4):969-979.

50. Mahler DA, Kerwin E, Ayers T, et al. FLIGHT1 and FLIGHT2: efficacy and safety of QVA149 (indacaterol/glycopyrrolate) versus its monocomponents and placebo in patients with chronic obstructive pulmonary disease. Am J Respir Crit Care Med. 2015;192(9): 1068-1079.

51. Wedzicha JA, Decramer M, Ficker JH, et al. Analysis of chronic obstructive pulmonary disease exacerbations with the dual bronchodilator QVA149 compared with glycopyrronium and tiotropium (SPARK): a randomised, double-blind, parallel-group study. Lancet Respir Med. 2013;1(3):199-209.

52. Rossi A, Kristufek P, Levine BE, et al; Formoterol in Chronic Obstructive Pulmonary Disease (FICOPD) II Study Group. Comparison of the efficacy, tolerability, and safety of formoterol dry powder and oral, slow-release theophylline in the treatment of COPD. Chest. 2002; 121(4):1058-1069.

53. Makino S, Adachi M, Ohta K, et al; Safety of Sustained-Release Theophylline and Injectable Methylxanthines Committee; Asthma Prevention and Management Guidelines Committee. A prospective survey on safety of sustained-release theophylline in treatment of asthma and COPD. Allergol Int. 2006;55(4):395-402

54. Fexer J, Donnachie E, Schneider A, et al. The effects of theophylline on hospital admissions and exacerbations in COPD patients: audit data from the Bavarian disease management program. Dtsch Arztebl Int. 2014;111(17):293-300.

55. Belda J, Leigh R, Parameswaran K, O’Byrne PM, Sears MR, Hargreave FE. Induced sputum cell counts in healthy adults. Am J Respir Crit Care Med. 2000;161(2 Pt 1):475-478.

56. Gao P, Zhang J, He X, Hao Y, Wang K, Gibson PG. Sputum inflammatory cell-based classification of patients with acute exacerbation of chronic obstructive pulmonary disease. PLoS One. 2013;8(5):e57678.

57. Martinez FJ, Calverley PM, Goehring UM, Brose M, Fabbri LM, Rabe KF. Effect of roflumilast on exacerbations in patients with severe chronic obstructive pulmonary disease uncontrolled by combination therapy (REACT): a multicentre randomised controlled trial. Lancet. 2015;385(9971):857-866

58. Albert RK, Connett J, Bailey WC, et al; COPD Clinical Research Network. Azithromycin for prevention of exacerbations of COPD. N Engl J Med. 2011;365(8):689-698.

59. Zykov K, Rvatcheva A, Pustovalov A, Averyanov A. Long-term treatment with clarithromycin of stage II COPD patients with frequent exacerbations. Eur Respir J. 2008;32 Suppl 52:1770.

60. Zheng JP, Kang J, Huang SG, et al. Effect of carbocisteine on acute exacerbation of chronic obstructive pulmonary disease (PEACE Study): a randomised placebo-controlled study. Lancet. 2008; 371(9629):2013-2018.

61. Tse H, Raiteri L, Wong KY, Ng LY, Yee KS, Tseng CZ. Benefits of high-dose $\mathrm{N}$-acetylcysteine to exacerbation-prone patients with COPD. Chest. 2014;146(3):611-623.

62. Dasgupta A, Neighbour H, Nair P. Targeted therapy of bronchitis in obstructive airway diseases. Pharmacol Ther. 2013;140(3): 213-222.

63. Moritz P, Steidle LJ, Felisbino MB, Kleveston T, Pizzichini MM, Pizzichini E. Determination of the inflammatory component of airway diseases by induced sputum cell counts: use in clinical practice. J Bras Pneumol. 2008;34(11):913-921.

64. Pascoe S, Locantore N, Dransfield MT, Barnes NC, Pavord ID. Blood eosinophil counts, exacerbations, and response to the addition of inhaled fluticasone furoate to vilanterol in patients with chronic obstructive pulmonary disease: a secondary analysis of data from two parallel randomised controlled trials. Lancet Respir Med. 2015; $3(6): 435-442$. 
65. Siva R, Green RH, Brightling CE, et al. Eosinophilic airway inflammation and exacerbations of COPD: a randomised controlled trial. Eur Respir J. 2007;29(5):906-913.

66. Singh D, Kolsum U, Brightling CE, Locantore N, Agusti A, Tal-Singer R; ECLIPSE investigators. Eosinophilic inflammation in COPD: prevalence and clinical characteristics. Eur Respir J. 2014; 44(6):1697-1700.
67. Pavord ID, Bafadhel M. Exhaled nitric oxide and blood eosinophilia: independent markers of preventable risk. J Allergy Clin Immunol. 2013; 132(4):828-829.

68. Negewo NA, McDonald VM, Baines KJ, et al. Peripheral blood eosinophils: a surrogate marker for airway eosinophilia in stable COPD. Int J Chron Obstruct Pulmon Dis. 2016;11:1495-1504.

International Journal of COPD

\section{Publish your work in this journal}

The International Journal of COPD is an international, peer-reviewed journal of therapeutics and pharmacology focusing on concise rapid reporting of clinical studies and reviews in COPD. Special focus is given to the pathophysiological processes underlying the disease, intervention programs, patient focused education, and self management protocols.

\section{Dovepress}

This journal is indexed on PubMed Central, MedLine and CAS. The manuscript management system is completely online and includes a very quick and fair peer-review system, which is all easy to use. Visit http://www.dovepress.com/testimonials.php to read real quotes from published authors.

Submit your manuscript here: http://www.dovepress.com/international-journal-of-chronic-obstructive-pulmonary-disease-journal 